\title{
Flavonol glycosides from Reseda lutea $\mathrm{L}$
}

\author{
Hatice Kızıltaşs, Melis Küçüksolak ${ }^{\mathrm{b}}$, Seda Duman ${ }^{\mathrm{b}}$, Erdal Bedir ${ }^{\mathrm{b}, *}$ \\ ${ }^{a}$ Hizan Vocational School, Plant and Animal Production Department, Bitlis Eren University, 13000, Bitlis, Turkey \\ ${ }^{\mathrm{b}}$ Department of Bioengineering, Faculty of Engineering, Izmir Institute of Technology, 35430, Urla-Izmir, Turkey
}

A R T I C L E I N F O

\section{Keywords:}

Reseda lutea L.

Resedaceae

Kaempferol tetraoside

Kaempferol coumaryltetraoside

Chemotaxonomy

\begin{abstract}
A B S T R A C T
Two new flavonol glycosides; kaempferol-3-O-[2-O-( $\beta$-D-xylopyranosyl)-3-O-( $\beta$-D-glucopyranosyl)]- $\alpha$-L-rhamnopyranosyl-7-O- $\alpha$-L-rhamnopyranoside (1) and kaempferol-3-O-[2-O-((6-O-trans-p-coumaryl)- $\beta$-D-glucopyranosyl)-3-O-( $\beta$-D-xylopyranosyl)]- $\alpha$-L-rhamnopyranosyl-7- $O$ - $\alpha$-L-rhamnopyranoside (2) were isolated from the aerial parts of Reseda lutea L., together with five known flavonol glycosides. Structural elucidation of the compounds was based on both spectroscopic evidence and reference data comparison. The new compounds are the first tetrasaccharidic secondary metabolites isolated from Resedaceae family.
\end{abstract}

\section{Introduction}

Reseda $\mathrm{L}$. is the largest genus of the Resedaceae family, with approximately 65 species mainly distributed in temperate areas of the western Palearctic, with a center of diversity in the Mediterranean basin and Southwestern Asia (Martín-Bravo et al., 2007). Reseda L. is represented by 18 taxa in Turkey, 10 of which are endemic to Turkey (Coode, 1965; Abdallah and de Wit, 1978; Martín-Bravo and JiménezMejías, 2013; Çilden et al., 2018). Previous phytochemical investigations on this genus revealed the presence of flavonoids (Berrehal et al., 2006, 2012; El-Sayed et al., 2001), non-protein aminoacids (Meier et al., 1979), glucosinolates (Olsen and Soerenson, 1980) and alkaloids (Lutfullin et al., 1977; Nakhotov and Tadzhibaev, 1977).

The extracts and secondary metabolites of Reseda were reported to have antimicrobial, antioxidant (Kumarasamy et al., 2002; Berrehal et al., 2010; Benmerache et al., 2012), anti-inflammatory (SusplugasTaillade et al., 1988; Bremner et al., 2009,), anti-HIV (Bedoya et al., 2001), antiproliferative and proapoptotic (Woelfle et al., 2010; Radulović et al., 2014), and neuroprotective (Kim et al., 2015) activities.

We here report the isolation and identification of two new compounds, a kaempferol tetraoside (1) and its p-coumaryl ester (2) together with five previously reported flavonoids.

\section{Results and discussion}

Structures of compounds $\mathbf{1}$ and $\mathbf{2}$ are shown in Fig. 1.

Compound 1 was isolated as a yellow amorphous powder and the molecular formula of $\mathbf{1}$ was determined as $\mathrm{C}_{38} \mathrm{H}_{48} \mathrm{O}_{23}$ due to the sodium adduct ion peak at $m / z 895.25803[\mathrm{M}+\mathrm{Na}]^{+}$obtained by HRMS. In the IR spectrum, absorption bands for hydroxyl $\left(3405 \mathrm{~cm}^{-1}\right)$, conjugated carbonyl $\left(1657 \mathrm{~cm}^{-1}\right)$, and aromatic $\left(1603 \mathrm{~cm}^{-1}, 1494 \mathrm{~cm}^{-1}\right.$, $1451 \mathrm{~cm}^{-1}$ ) groups were apparent. The ${ }^{1} \mathrm{H}$-NMR resonances of two $m$ coupled protons at $\delta 6.81(\mathrm{~d}, J=1.8 \mathrm{~Hz})$ and $6.96(\mathrm{~d}, J=1.9 \mathrm{~Hz})$, which correlated with carbons at $\delta 100.9$ and 95.4 in the HSQC spectrum, were characteristic of the two meta-related 6- and 8- protons of a 5,7-dihydroxy A-ring of a flavonoid skeleton (Khallouki et al., 2000). Additionally, in the low-field of the ${ }^{1} \mathrm{H}$-NMR spectrum, $4 \mathrm{H}$ were observed as coupled doublets $\left(\mathrm{A}_{2} \mathrm{~B}_{2}\right.$ system) at $\delta 8.09(2 \mathrm{H}, \mathrm{d}, J=8.6 \mathrm{~Hz}$, $\mathrm{H}-2^{\prime}$ and $\left.\mathrm{H}-6^{\prime}\right)$ and $7.44\left(2 \mathrm{H}, \mathrm{d}, J=8.7 \mathrm{~Hz}, \mathrm{H}-3^{\prime}\right.$ and $\left.\mathrm{H}-5^{\prime}\right)$, suggesting that the B-ring was para-disubstituted. Therefore, the aglycon moiety of $\mathbf{1}$ was characterized as flavonol or a flavonol substituted in C-3, a wellknown flavonoid aglycone. The resonances of four anomeric protons, observed at $\delta 6.29(\mathrm{~s}), 6.27(\mathrm{~s}), 5.48$ (d, $J=7.6 \mathrm{~Hz}$ ) and 5.31 (d, $J=7.4 \mathrm{~Hz}$ ), suggested that compound 1 was a tetra saccharidic kaempferol derivative. The structure of the oligosaccharide unit was elucidated using the 2D NMR experiments. The correlations deduced from the COSY spectrum allowed the assignments of all proton resonances within each sugar residue, starting from the well-isolated anomeric proton signals. HSQC experiment, which correlated all proton resonances with those of each corresponding carbon, permitted the assignments of the interglycosidic linkages by comparison of the observed carbon chemical shifts with those of the corresponding methylpyranosides, considering the known effects of glycosidation. Thus, on the basis of the proton and carbon chemical shifts, multiplicity of the signals and absolute values of coupling constants, the four sugar residues were identified as $\beta$-xylopyranosyl, $\beta$-glucopyranosyl and $\alpha$ rhamnopyranosyl. The absolute configurations of the sugar residues

\footnotetext{
* Corresponding author.

E-mail address: erdalbedir@iyte.edu.tr (E. Bedir).
} 


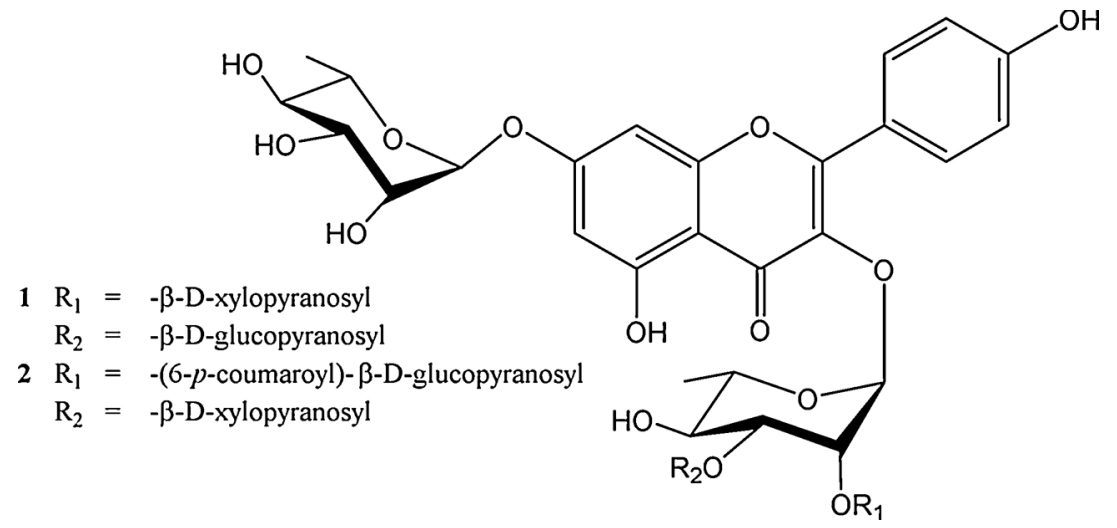

Fig. 1. Structures of compounds 1 and $\mathbf{2}$.

were established to be D for glucose and xylose, and L for rhamnose based on the optical rotation data of the isolated sugars and taking into consideration the biogenetic evidence derived from Reseda flavonoids.

The absence of any ${ }^{13} \mathrm{C}$-NMR glycosidation shifts for the 7-Orhamnopyranosyl, xylopyranosyl and glucopyranosyl residues suggested these sugars to be terminal. The position of each sugar residue was unambiguously determined by the HMBC experiment (Fig. 2), which showed long-range correlations between H-1" ${ }_{\text {rhm }}(\delta 6.29$ brs) and C-3 $(\delta 136.1), \mathrm{H}-1{ }^{\prime \prime}{ }_{\mathrm{xyl}}\left(\delta\right.$ 5.31) and C-2" ${ }_{\mathrm{rhm}}(\delta 80.3), \mathrm{H}-1{ }^{\prime \prime}{ }_{\text {glu }}(\delta$ $5.31)$ and C-3" ${ }_{\text {rhm }}(\delta 81.8)$, and H- $1 "{ }^{\prime \prime}{ }_{\text {rhm }}(\delta 6.27)$ and C-7 ( $\left.\delta 163.3\right)$. On the basis of these data, the structure of compound 1 was established as kaempferol-3-O-[2-O-( $\beta$-D-xylopyranosyl)-3-O-( $\beta$-D-glucopyranosyl)]- $\alpha$ L-rhamnopyranosyl-7-O- $\alpha$-L-rhamnopyranoside.

Compound 2 was also isolated as a yellow amorphous powder. The molecular formula of 2 was determined as $\mathrm{C}_{47} \mathrm{H}_{54} \mathrm{O}_{25}$ from its HRMS $\left(\mathrm{m} / \mathrm{z} 1041.29511[\mathrm{M}+\mathrm{Na}]^{+}\right)$. The IR spectrum of 2 showed absorptions of ester carbonyl $\left(1688 \mathrm{~cm}^{-1}\right)$, hydroxyl $\left(3422 \mathrm{~cm}^{-1}\right)$, conjugated carbonyl $\left(1655 \mathrm{~cm}^{-1}\right)$, aromatic $\left(1604 \mathrm{~cm}^{-1}, 1494 \mathrm{~cm}^{-1}, 1451 \mathrm{~cm}^{-1}\right)$ groups. The ${ }^{1} \mathrm{H}$ - and ${ }^{13} \mathrm{C}$ NMR spectra of 2 showed the presence of aromatic and sugar moiety resonances.

The ${ }^{1} \mathrm{H}$-NMR and COSY spectra revealed three distinct aromatic systems. First one displayed resonances at $\delta 7.48(2 \mathrm{H}, \mathrm{d}, J=8.1 \mathrm{~Hz}, \mathrm{H}-$ 2"'”' and H-6"'”') and 6.97 (2H, d, $J=7.8 \mathrm{~Hz}, \mathrm{H}-3$ '"'” and $\mathrm{H}-5$ "'”'). Considering the coupling pattern, i.e., two ortho couplings, it was inferred that 2 had a para disubstituted-aromatic ring. A trans disubstituted double bond $(\delta 7.97, \mathrm{~d}, J=15.9 \mathrm{~Hz}$ and $\delta 6.68$, d, $J=15.9 \mathrm{~Hz}$ ) was also observed. In the ${ }^{13} \mathrm{C}$-NMR spectrum of 2 , the resonances for two olefinic carbons ( $\delta 146.1$ and $\delta 115.4)$, attributed to the trans double-bond system, and the carbonyl carbon resonance at $\delta 168.1$ helped us to deduce a $p$-coumaryl residue in 2 . The long-range

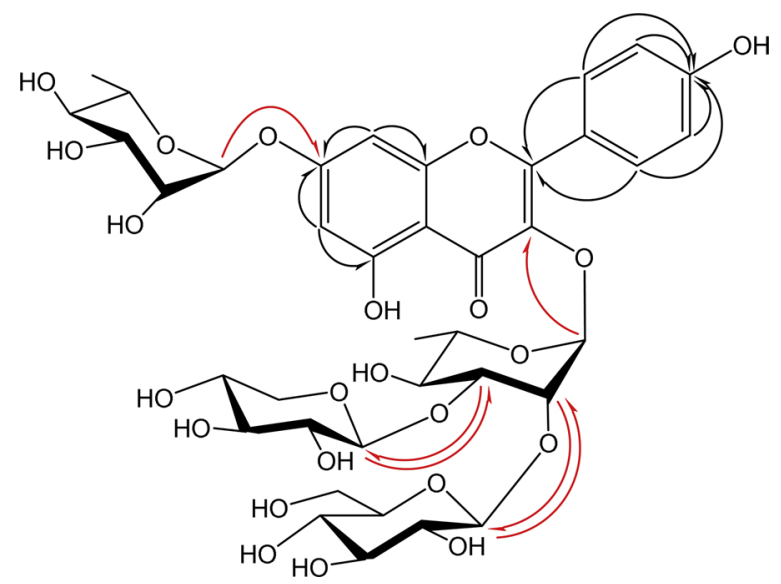

Fig. 2. Key HMBC's of compound 1 (arrows from $\mathrm{H}$ to $\mathrm{C}$ ). correlations in the HMBC spectrum between olefinic protons (H-7"'”' and H-8"'”') and carbonyl carbon (C-9"'"')/aromatic carbons (C-2"'”, and C-5"'"') substantiated the presence of $p$-coumaric acid moiety. After subtraction of the 9 carbon resonances from the aromatic region, the remaining resonances were attributable to a flavonoid skeleton. Detailed inspection of the 1D NMR spectra revealed that the remaining aromatic systems were consistent with the presence of kaempferol as in 1 (Table 1 and Fig. 1). All the assignments of the aglycone moiety were secured by 2D NMR experiments, which also revealed that the oligosaccharide moieties of $\mathbf{2}$ were identical of compound $\mathbf{1}$; however, a number of discrepancies were evident for glycosidic linkages. The HMBC spectrum (Fig. 3) displayed long-range correlations from $\mathrm{H}-1{ }^{\prime}$ rhm ( $\delta$ 6.37) to C-3 ( $\delta 136.1), \mathrm{H}-1{ }^{\prime \prime}$ glu $(\delta 5.38)$ to C-2" ${ }_{\text {rhm }}(\delta 79.9), \mathrm{H}-1{ }^{\prime \prime}{ }_{\mathrm{xyl}}$ $(\delta 5.47)$ to $\mathrm{C}-3{ }^{\prime}{ }_{\text {rhm }}(\delta 82.0)$, and H-1"'”' ${ }_{\text {rhm }}(\delta$ 6.27) to C-7 $(\delta 163.3)$ verifying that the position of xylopyranosyl and glucopyranosyl residues switched in the structure of 2 compared to 1 . The ${ }^{1} \mathrm{H}-\mathrm{NMR}$ spectrum of 2 also showed that methylene protons of glucose $\left(\mathrm{H}_{2}-6\right.$ "') shifted downfield to $\delta 5.15(\mathrm{~m})$ and 4.90 (dd, $J=11.6$ and $7.4 \mathrm{~Hz}$ ) confirming acylation at the C-6(O) position (Kim et al., 1998; Liu et al., 1999). The linkage of the $p$-coumaryl group to the C-6(O) of the glucose was also confirmed by the cross peak between the carbonyl carbon at $\delta 168.1$ and $\mathrm{H}_{2}-6 " '$ at $\delta 4.90$ (Bloor, 1999).

The absolute configuration of sugar units were established after hydrolysis of the flavonoid fraction of $R$. lutea, and confirmed by the optical rotation data of the isolated sugars and biogenetic considerations.

Consequently, the structure of $\mathbf{2}$ was established as kaempferol-3-O[2-O-((6-O- trans-p-coumaryl)- $\beta$-D-glucopyranosyl)-3-O-( $\beta$-D-xylopyranosyl)]- $\alpha$-L-rhamnopyranosyl-7- $O$ - $\alpha$-L-rhamnopyranoside.

The known compounds kaempferol-3-O-[2-O-( $\beta$-D-xylopyranosyl)]$\alpha$-L-rhamnopyranosyl-7-O- $\alpha$-L-rhamnopyranoside (3), kaempferol-3-O$\beta$-D-glucopyranosyl-7-O- $\alpha$-L-rhamnopyranoside (4a), isorhamnetin-3-O$\beta$-D-glucopyranosyl-7-O- $\alpha$-L-rhamnopyranoside (4b), kaempferol-3,7di-O- $\alpha$-L-rhamnopyranoside (5a) and isorhamnetin-3,7-di-O- $\alpha$-rhamnopyranoside $(\mathbf{5 b})$ were also isolated and identified by comparison of their ${ }^{1}$ H-NMR spectra with literature data (Berrehal et al., 2012).

Secondary metabolites of Resedaceae family are mainly flavonoids with flavone, flavonol and isoflavone skeletons. The previous phytochemical investigations on Reseda genus revealed the presence of luteolin, luteolin-7-O glucoside, luteolin 4:O-glucoside and apigenin from $R$. luteola (Woelfle et al., 2010; Moiteiro et al., 2008), whereas quercetin, isorhamnetin and kaempferol and their glycosides from $R$. villosa (Berrahal et al., 2006), R. muricata (El-Sayed et al., 2001) and $R$. lutea (Rzadkowska-Bodalska, 1969) were also identified. Moreover, Yuldashev et al. (1996) reported flavonol diglycosides of kaempferol, quercetin and isorhamnetin from $R$. luteola.

Two new compounds named kaempferol-3-O-[2-O-( $\beta$-D-xylopyranosyl)-3-O-( $\beta$-D-glucopyranosyl)]- $\alpha$-L-rhamnopyranosyl-7-O- $\alpha$-Lrhamnopyranoside and kaempferol-3-O-[2-O-((6-O-trans-p-coumaryl)- 
Table 1

${ }^{1} \mathrm{H}$-NMR and ${ }^{13} \mathrm{C}$ assignments of $\mathbf{1}$ and $\mathbf{2}$ in Pyridine-d5.

\begin{tabular}{|c|c|c|c|c|}
\hline \multirow[t]{2}{*}{$\mathrm{H} / \mathrm{C}$} & \multicolumn{2}{|l|}{1} & \multicolumn{2}{|l|}{2} \\
\hline & $\delta_{\mathrm{H}}(J$ in $\mathrm{Hz})$ & $\delta_{\mathrm{C}}$ & $\delta_{\mathrm{H}}(J$ in $\mathrm{Hz})$ & $\delta_{\mathrm{C}}$ \\
\hline \multicolumn{5}{|l|}{1} \\
\hline 2 & & 158.9 & & 158.5 \\
\hline 3 & & 136.1 & & 136.1 \\
\hline 4 & & 179.6 & & 179.5 \\
\hline 5 & & 162.9 & & 162.8 \\
\hline 6 & $6.81 \mathrm{~d}(1.8)$ & 100.9 & $6.73 \mathrm{brs}$ & 100.9 \\
\hline 7 & & 163.3 & & 163.3 \\
\hline 8 & $6.96 \mathrm{~d}(1.9)$ & 95.4 & $6.94 \mathrm{brs}$ & 95.3 \\
\hline 9 & & 157.5 & & 157.5 \\
\hline 10 & & 107.5 & & 107.5 \\
\hline 1 & & 121.7 & & 121.8 \\
\hline 2 & $8.09 \mathrm{~d}(8.6)$ & 132.1 & $8.14 \mathrm{~d}(8.0)$ & 132.1 \\
\hline $3^{\prime}$ & $7.44 \mathrm{~d}(8.7)$ & 117.2 & $7.41 \mathrm{~d}(7.9)$ & 117.1 \\
\hline $4^{\prime}$ & & 162.7 & & 162.6 \\
\hline $5^{\prime}$ & $7.44 \mathrm{~d}(8.7)$ & 117.2 & $7.41 \mathrm{~d}(7.9)$ & 117.1 \\
\hline $6^{\prime}$ & $8.09 \mathrm{~d}(8.6)$ & 132.1 & $8.14 \mathrm{~d}(8.0)$ & 132.1 \\
\hline \multicolumn{3}{|c|}{$\alpha-\mathrm{L}-\mathrm{Rhm}$ (at C-3) } & \multicolumn{2}{|l|}{$\alpha-\mathrm{L}-\mathrm{Rhm}$ (at C-3) } \\
\hline 1" & $6.29 \mathrm{brs}$ & 103 & 6.37 brs & 102.6 \\
\hline $2 "$ & 5.24 brs & 80.3 & 5.26 brs & 79.9 \\
\hline 3" & 4.83 dd $(9.5,3.1)$ & 81.8 & $4.84 \mathrm{~m}$ & 82.0 \\
\hline $4 "$ & $4.36 \mathrm{~m}$ & 72.3 & $4.36 \mathrm{~m}$ & 72.1 \\
\hline 5" & $4.47 \mathrm{~m}$ & 72.1 & $4.32 \mathrm{~m}$ & 72.1 \\
\hline 6" & $1.37 \mathrm{~d}(6.0)$ & 18.6 & $1.34 \mathrm{~d}(4.4)$ & 18.8 \\
\hline \multicolumn{3}{|c|}{$\beta$-D-Xyl (at C-2 of Rhm at C-3) } & \multicolumn{2}{|c|}{$\beta$-D-Glu (at C-2 of Rhm at C-3) } \\
\hline $1 ”$ & $5.31 \mathrm{~d}(7.4)$ & 107.3 & $5.38 \mathrm{~d}(7.5)$ & 107.0 \\
\hline 2”' & $4.0 \mathrm{~m}$ & 76.0 & $3.97 \mathrm{~m}$ & 76.0 \\
\hline $3 ”$ & $4.24 \mathrm{~m}$ & 78.8 & $4.25 \mathrm{~m}$ & 78.7 \\
\hline $4 ” '$ & $4.15 \mathrm{~m}$ & 71.5 & $4.02 \mathrm{~m}$ & 72.3 \\
\hline $5 ”$ & $4.30 \mathrm{~m} ; 3.73 \mathrm{t}(10.5)$ & 67.8 & $4.17 \mathrm{~m}$ & 76.3 \\
\hline $6 ”$ & - & - & $4.90 \mathrm{dd}(11.6,7.4) ; 5.15 \mathrm{~m}$ & 65.3 \\
\hline \multicolumn{3}{|c|}{$\beta-D-G l u$ (at C-3 of Rhm at C-3) } & \multicolumn{2}{|l|}{$\beta-\mathrm{D}-\mathrm{Xyl}$ (at C-3 of Rhm at C-3) } \\
\hline $1 " ”$ & $5.48 \mathrm{~d}(7.6)$ & 106.4 & $5.47 \mathrm{~d}(7.1)$ & 106.8 \\
\hline 2"”' & $4.15 \mathrm{~m}$ & 76.2 & $4.21 \mathrm{~m}$ & 76.1 \\
\hline 3"” & $4.23 \mathrm{~m}$ & 78.6 & $4.14 \mathrm{~m}$ & 78.7 \\
\hline 4"”' & $4.29 \mathrm{~m}$ & 72.0 & $4.14 \mathrm{~m}$ & 71.6 \\
\hline 5"” & $4.00 \mathrm{~m}$ & 79.1 & $\begin{array}{l}4.31 \mathrm{dd}(10.7,4.0) ; 3.77 \mathrm{t} \\
(10.4)\end{array}$ & 67.9 \\
\hline 6"” & $\begin{array}{l}4.53 \text { dd }(11.6,2.0) ; 4.36 \\
\mathrm{~m}\end{array}$ & 63.1 & - & - \\
\hline \multicolumn{3}{|c|}{$\alpha$-L-Rhm (at C-7) } & \multicolumn{2}{|l|}{$\alpha-\mathrm{L}-\mathrm{Rhm}$ (at C-7) } \\
\hline $1 " ” '$ & 6.27 brs & 100.5 & 6.27 brs & 100.5 \\
\hline 2"”' & $4.72 \mathrm{brs}$ & 72.1 & $4.70 \mathrm{brs}$ & 72.3 \\
\hline 3"”' & 4.67 dd $(9.1,3.3)$ & 72.9 & $4.60 \mathrm{~m}$ & 72.8 \\
\hline 4"”' & $4.39 \mathrm{~m}$ & 74.0 & $4.40 \mathrm{~m}$ & 74.1 \\
\hline $5 " ” '$ & $4.30 \mathrm{~m}$ & 71.9 & $4.36 \mathrm{~m}$ & 71.9 \\
\hline \multirow[t]{2}{*}{ 6"”' } & $1.66 \mathrm{~d}(6.0)$ & 19.1 & $1.67 \mathrm{~d}(5.9)$ & 19.4 \\
\hline & & & $p$-coumaric acid & \\
\hline $1 " ”, "$ & & & & 126.4 \\
\hline 2"'”' & & & $7.48 \mathrm{~d}(8.1)$ & 130.9 \\
\hline 3"'”' & & & $6.97 \mathrm{~d}(7.8)$ & 117.0 \\
\hline 4"'”" & & & & 161.8 \\
\hline 5"'”" & & & $6.97 \mathrm{~d}(7.8)$ & 117.0 \\
\hline 6"'”" & & & $7.48 \mathrm{~d}(8.1)$ & 130.9 \\
\hline 7"”'” & & & $7.97 \mathrm{~d}(15.9)$ & 146.1 \\
\hline 8"'”" & & & $6.68 \mathrm{~d}(15.9)$ & 115.4 \\
\hline 9"'”" & & & & 168.1 \\
\hline
\end{tabular}

$\beta$-D-glucopyranosyl)-3-O-( $\beta$-D-xylopyranosyl)]- $\alpha$-L-rhamnopyranosyl 7$O$ - $\alpha$-L-rhamnopyranoside are reported here as new ones as well as first tetrasaccharidic secondary metabolites from the family Resedaceae (ElSayed et al., 2001; Berrahal et al., 2006; Berrehal et al., 2012).

\section{Experimental}

\subsection{General procedures}

High resolution mass spectra were obtained on Agilent 1200/6530 Instrument -HRTOFMS. IR spectra were obtained on Perkin Elmer Spectrum 100 FT-IR spectrometer. Optical rotation measurements were measured with ADP 410 Digital Polarimeter (Bellingham + Stanley

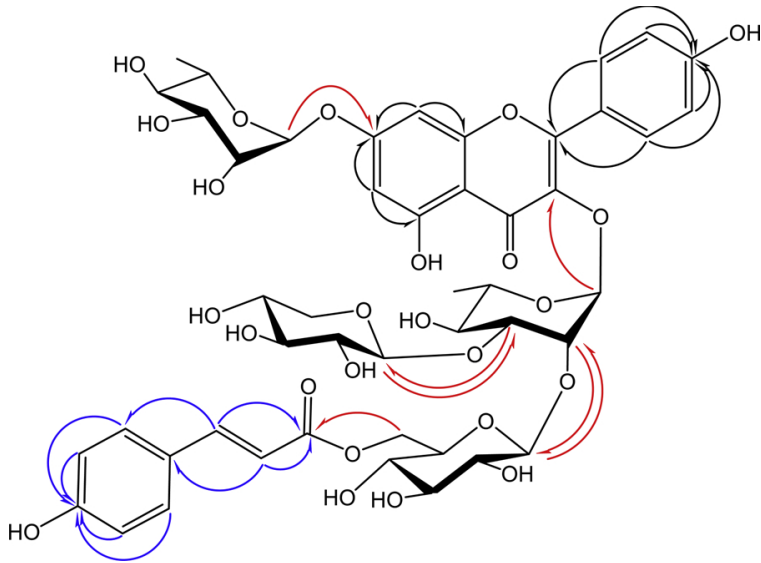

Fig. 3. Key HMBC's of compound 2 (arrows from $\mathrm{H}$ to $\mathrm{C}$ ).

Ltd.) in distilled $\mathrm{H}_{2} \mathrm{O}$. 1D and 2D (COSY, HMBC, HSQC and NOESY) NMR spectra were recorded on Varian $400-\mathrm{NMR}(400 \mathrm{MHz})$ spectrometer with TMS as internal standard at room temperature. 2D NMR spectra were run using standard Varian pulse programs. Column chromatography was carried out on silica gel (JT Baker, $40 \mathrm{~mm}$ ), Sephadex LH-20 (Amersham Biosciences, 17-0090-02). TLC analyses were carried out on silica gel $60 \mathrm{~F}_{254}$ (Merck) and RP-18 $\mathrm{F}_{254 \mathrm{~s}}$ (Merck) pre-coated aluminum plates. Compounds were detected by UV $(254-366 \mathrm{~nm})$ and spraying $20 \% \mathrm{H}_{2} \mathrm{SO}_{4}$ reagent followed by heating.

\subsection{Plant material}

R. lutea L. var. lutea $\mathrm{L}$. was collected from Kagizman, Kars, Turkey in June $2017\left(40^{\circ} 08^{\prime} 54.7^{\prime \prime} \mathrm{N} ; 43^{\circ} 06^{\prime} 44.1^{\prime \prime} \mathrm{E}\right)$. The plant was confirmed by Dr. Ademi Fahri Pirhan (Deparment of Biology, Faculty of Sciences, Ege University, Izmir, Turkey). Voucher specimens (EGE 43,161) have been deposited at the herbarium of the Department of Botany, Faculty of Science, Ege University, Izmir, Turkey.

\subsection{Extraction and isolation}

The air-dried and grounded aerial parts of plant $(620 \mathrm{~g})$ were extracted with methanol $(\mathrm{MeOH})(30 \%)(2.6 \mathrm{~L})$ for $8 \mathrm{~h}$, under reflux. After filtration, the solvent was evaporated under reduced pressure to dryness, and yielded $14.75 \mathrm{~g}$ extract. The methanolic extract was subjected to open column chromatography using D101 resin $(250 \mathrm{~g})\left(\mathrm{H}_{2} \mathrm{O}: \mathrm{MeOH}\right.$, $80: 20$ to $0: 100 ; 20 \%$ decreasing polarity) to give 103 fractions (Fractions A1-A103). Based on the TLC profiles, the flavonoid-rich fractions (Fr.B: A56-79; $637.5 \mathrm{mg}$ ) were selected for further purification. Fr. B was chromatographed over silica gel $(125 \mathrm{~g})$ using EtOAc:MeOH: $\mathrm{H}_{2} \mathrm{O} \quad(100: 10: 5, \quad 750 \mathrm{~mL} ; \quad 100: 12.5: 7.5, \quad 2530 \mathrm{~mL}$; $100: 15: 10,2000 \mathrm{~mL} ; 100: 17.5: 13.5,520 \mathrm{~mL}$ ) to yield 256 fractions. Fractions B13-B24 (25 mg) was separated by Sephadex LH-20 (35 g) using $\mathrm{MeOH}(100 \%, 350 \mathrm{~mL})$ to give $\mathbf{5 a - 5 b}$ as a mixture $(4.8 \mathrm{mg})$. Fractions B28-B44 (35 mg) re-chromatographed over Sephadex LH-20 (35 g) using $\mathrm{MeOH}(100 \%, 300 \mathrm{~mL})$ to afford 40 fractions (D). Fractions D20-D40 (28.6 mg) were combined and subjected to Sephadex LH-20 ( $35 \mathrm{~g})$ using $\mathrm{MeOH}(100 \%, 350 \mathrm{~mL})$ to give $4 \mathbf{a}-4 \mathbf{b}$ as a mixture $(13.6 \mathrm{mg})$. Fractions B51-B59 $(13.6 \mathrm{mg})$ were combined to afford compound $3(17.3 \mathrm{mg})$. Fractions B90-B126 $(38.6 \mathrm{mg})$ was purified on Sephadex LH-20 (35 g) using $\mathrm{MeOH}(100 \%, 450 \mathrm{~mL})$ to give 2 (17.8 mg). Fractions B157-B198 (54.4 mg) was chromatographed on a silica gel column (40 g) using EtOAc: $\mathrm{MeOH}: \mathrm{H}_{2} \mathrm{O}(100: 10: 5,786 \mathrm{~mL}$; $100: 20: 15,250 \mathrm{~mL})$ to afford 80 fractions. Fraction G36-G53 (27.2 mg) were combined and re-chromatographed over silica gel column (12 g) using Petroleum ether: $\mathrm{CHCl}_{3}: \mathrm{MeOH}: \mathrm{H}_{2} \mathrm{O}$ (5:60:30:2300 mL; 5:60:40:7.5, $100 \mathrm{~mL})$ to afford $1(11.1 \mathrm{mg})$. 


\subsubsection{Kaempferol-3-O-[2-O-( $\beta$-D-xylopyranosyl)-3-O-( $\beta-D-$}

glucopyranosyl)]- $\alpha$-L-rhamnopyranosyl-7-O- $\alpha$-L-rhamnopyranoside (1)

Yellow amorphous powder; QTOF-MS: $m / z=895.25803$ $[\mathrm{M}+\mathrm{Na}]^{+}$(calcd. for $\mathrm{C}_{38} \mathrm{H}_{48} \mathrm{O}_{23} \mathrm{Na}$ : 895.24781) (positive mode); $[\alpha]_{\mathrm{D}}^{20}-5.17\left(c 0.0008, \mathrm{H}_{2} \mathrm{O}\right)$; IR (KBr) $\nu$ max $3405,1657,1603,1494$, $1451 \mathrm{~cm}^{-1}$; ${ }^{1} \mathrm{H}$ NMR (Pyridine- $\mathrm{d}_{5}, 400 \mathrm{MHz}$ ) and ${ }^{13} \mathrm{C}$ NMR (Pyridine$\mathrm{d}_{5}, 100 \mathrm{MHz}$ ) data: see Table 1 .

\subsubsection{Kaempferol-3-O-[2-O-((6-O-trans-p-coumaryl)- $\beta$ - $D$ -} glucopyranosyl)-3-O-( $\beta$-D-xylopyranosyl)]- $\alpha$-L-rhamnopyranosyl-7-O- $\alpha-L_{-}^{-}$ rhamnopyranoside (2)

Yellow amorphous powder; QTOF-MS: $m / z=1041.29511$ $[\mathrm{M}+\mathrm{Na}]^{+}$(calcd. for $\mathrm{C}_{47} \mathrm{H}_{54} \mathrm{O}_{25} \mathrm{Na}$ : 1041.284618) (positive mode); $[\alpha]_{\mathrm{D}}^{20}-1.63\left(c 0.001, \mathrm{H}_{2} \mathrm{O}\right)$; IR (KBr) $\nu \max 3422,1688,1655,1604$, 1494, $1451 \mathrm{~cm}^{-1}$; ${ }^{1} \mathrm{H}$ NMR (Pyridine- $\mathrm{d}_{5}, 400 \mathrm{MHz}$ ) and ${ }^{13} \mathrm{C}$ NMR (Pyridine- $\mathrm{d}_{5}, 100 \mathrm{MHz}$ ) data: see Table 1 .

\subsubsection{Kaempferol-3-O-[2-O-( $\beta$-D-xylopyranosyl)]- $\alpha$-L-rhamnopyranosyl-7-} $O$ - $\alpha$-L-rhamnopyranoside (3)

Yellow amorphous powder; ${ }^{1} \mathrm{H}-\mathrm{NMR}(400 \mathrm{MHz}$, DMSO-d6) data was identical to those reported in the literature (Berrehal et al., 2012).

\subsubsection{Kaempferol-3-O- $\beta$-D-glucopyranosyl-7-O- $\alpha$-L-rhamnopyranoside} (4a) and isorhamnetin-3-O- $\beta$-D-glucopyranosyl-7-O- $\alpha$-L-rhamnopyranoside (4b)

Yellow amorphous powder; 4a (major) and $4 \mathrm{~b}$ (minor) were isolated as a mixture. ${ }^{1} \mathrm{H}$-NMR (400 MHz, DMSO-d6) data was identical to those reported in the literature (Berrehal et al., 2012).

\subsubsection{Kaempferol-3,7-di-O- $\alpha-L-r h a m n o p y r a n o s i d e ~(5 a)$ and isorhamnetin-} 3,7-di-O- $\alpha$-L-rhamnopyranoside (5b)

Yellow amorphous powder; 5a (major) and $\mathbf{5 b}$ (minor) were isolated as a mixture. ${ }^{1} \mathrm{H}-\mathrm{NMR}$ (400 MHz, DMSO-d6) data was identical to those reported in the literature (Berrehal et al., 2012).

\subsection{Acid hydrolysis}

The crude flavonoid mixture of fraction B199-233 $(68.8 \mathrm{mg})$ was heated at $60{ }^{\circ} \mathrm{C}$ with $1: 10.5 \mathrm{~N} \mathrm{H}_{2} \mathrm{SO}_{4}$-dioxane $(3 \mathrm{~mL})$ for $2 \mathrm{~h}$, and then evaporated in vacuo. The solution was partitioned with EtOAc, and the $\mathrm{H}_{2} \mathrm{O}$ layer was neutralized with $0.5 \mathrm{M} \mathrm{NaOH}$. After gaining the hydrolyzed mixture, two monosaccharides were purified utilizing normalphase silica gel as stationary phase $(20 \times 120 \mathrm{~mm}, 20 \mathrm{~g})$ eluting with $\mathrm{CHCl}_{3}: \mathrm{MeOH}: \mathrm{H}_{2} \mathrm{O}$ solvent system (70:30:3; 61:32:7; 60:40:10). After purification, the obtained sugar units were identified by comparison with authentic samples using TLC in $n$ - $\mathrm{BuOH}: \mathrm{CH}_{3} \mathrm{COOH}: \mathrm{H}_{2} \mathrm{O}$ (4:1:5) system and their identity was confirmed after preparative TLC in the same solvent. The optical rotation of each purified sugar was measured to afford L-rhamnose $\left([\alpha]_{\mathrm{D}}^{20}+40.0, c 0.005, \mathrm{H}_{2} \mathrm{O}\right)$ and D-glucose $\left([\alpha]_{\mathrm{D}}^{20}\right.$ +13.15 , c 0.011, $\mathrm{H}_{2} \mathrm{O}$ ). The chromatographic separation studies yielded insufficient amount of xylose to obtain its optical rotation. As xylose derives from glucose via oxidation of C-6 followed by decarboxylation, its absolute configuration was directly suggested to be $\mathrm{D}$ based on the biosynthetic foundation.

\section{Acknowledgments}

This study is derived from BEBAP 2017.20 which is implemented with the support of Bitlis Eren University Scientific Research Projects Coordination Unit. We would like to thank Bitlis Eren University Research Projects Coordination Unit for its support.

\section{Appendix A. Supplementary data}

Supplementary material related to this article can be found, in the online version, at doi:https://doi.org/10.1016/j.phytol.2019.01.027.

\section{References}

Abdallah, M.S., De Wit, H.C.D., 1978. The Resedaceae: a taxonomical revision of the family (final installment). Mededeelingen van de Landbouwhoogeschool te Wageningen 78 (14), 1-318.

Bedoya, L.M., Sanchez-Palomino, S., Abad, M.J., Bermejo, P., Alcami, J., 2001. Anti-HIV activity of medicinal plant extracts. J. Ethnopharmacol. 77, 113-116.

Benmerache, A., Berrehal, D., Khalfallah, A., Kabouche, A., Semra, Z., Kabouche, Z. 2012. Antioxidant, antibacterial activities and flavonoids of Reseda phyteuma L. Der Pharmacia Lettre 4 (6), 1863-1867.

Berrehal, D., Kabouche, A., Kabouche, Z., Bruneau, C., 2006. Flavonoid glycosides from Reseda villosa (Resedaceae). Biochem. Syst. Ecol. 34, 777-779.

Berrehal, D., Khalfallah, A., Bencharif-Betina, S., Kabouche, Z., Kacem, N., Kabouche, A., Calliste, C.A., Duroux, J.L., 2010. Comparative antioxidant activity of two Algerian Reseda species. Chem. Nat. Compd. 46 (3), 456-458.

Berrehal, D., Khalfallah, A., Kabouche, A., Karioti, A., Bilia, A.R., Goren, A.C., Kabouche, Z., 2012. Flavonol glycosides of Reseda arabica (Resedaceae). Rec. Nat. Prod. 6 (4), 368-370.

Bloor, S.J., 1999. Novel pigments and copigmentation in the blue marguerite daisy. Phytochemistry 50, 1395-1399.

Bremner, P., Rivera, D., Calzado, M.A., Obón, C., Inocencio, C., Beckwith, C., Fiebich, B.L., Munoz, E., Heinrich, M., 2009. Assessing medicinal plants from South-Eastern Spain for potential anti-inflammatory effects targeting nuclear factor-Kappa B and other pro-inflammatory mediators. J. Ethnopharmacol. 124, 295-305.

Çilden, E., Yildirimli, S., Zare, G., Martín-Bravo, S., 2018. Rediscovery of the restricted endemic Reseda balansae (Resedaceae) in Turkey. Phytotaxa 362 (1), 087-096.

Coode, M.J.E., 1965. Reseda L. In: In: Davis, P.H. (Ed.), Flora of Turkey and the East Aegean Islands., vol. 1. Edinburgh University Press, pp. 498-506.

El-Sayed, N.H., Omara, N.M., Yousef, A.K., Farag, A.M., Mabry, T.J., 2001. Kaempferol triosides from Reseda muricata. Phytochemistry 57, 575-578.

Khallouki, F., Hmamouchi, M., Younos, C., Soulimani, R., Essassi, E.M., 2000. A new flavonoid from the aerial parts of Chrysanthemum viscidehirtum. Fitoterapia 71, 413-416.

Kim, H.J., Woo, E.-R., Shin, C.-G., Park, H., 1998. A new flavonol glycoside gallate ester from Acer okamotoanum and its inhibitory activity against human immunodeficiency virus-1 (HIV-1) integrase. J. Nat. Prod. 61, 145-148.

Kim, S.S., Seo, J.Y., Lim, S.S., Suh, H.J., Kim, L., Kim, J.S., 2015. Neuroprotective effect of Reseda luteola L. extract in a mouse neuronal cell model. Food Sci. Biotechnol. 24 (1), 333-339.

Kumarasamy, Y., Cox, P.J., Jaspars, M., Nahar, L., Sarker, S.D., 2002. Screening seeds of Scottish plants for antibacterial activity. J. Ethnopharmacol. 83, 73-77.

Liu, H., Orjala, J., Sticher, O., Rali, T., 1999. Acetylated flavonol gylcosides from leaves of Stenochlaena palustris. J. Nat. Prod. 62, 70-75.

Lutfullin, K.L., Tadzhibaev, M.M., Abdullaev, U.A., Malikov, V.M., Yunusov, S.Y., 1977. Alkaloids of Reseda luteola. Chem. Nat. Compd. 12 (5), 559-563.

Martín-Bravo, S., Jiménez-Mejías, P., 2013. Reseda minoica (Resedaceae), a new species from the eastern Mediterranean region. Ann. Bot. Fenn. 50, 55-60.

Martín-Bravo, S., Meimberg, H., Luceño, M., Märkl, W., Valcárcel, V., Bräuchler, C., Vargas, P., Heubl, G., 2007. Molecular systematics and biogeography of Resedaceae based on ITS and trnL-F sequences. Mol. Phylogenet. Evol. 44, 1105-1120.

Meier, L.K., Olsen, O., Soerenson, H., 1979. Acidic amino acids in Reseda luteola. Phytochemistry 18, 1505-1509.

Moiteiro, C., Gaspar, H., Rodrigues, A.I., Lopes, J.F., Carnide, V., 2008. HPLC quantification of dye flavonoids in Reseda luteola L. from Portugal. J. Sep. Sci. 31, 3683-3687.

Nakhotov, I.K., Tadzhibaev, M., 1977. M. Malikov, V. M. Yunusov, S. Yu., Alkaloids ofReseda lutea. Khim. Prir. Soedin. 3, 424-425.

Olsen, O., Soerenson, H., 1980. Glucosinolates and amines in Reseda media. Phytochemistry 19, 1783-1787.

Radulović, N.S., Zlatković, D.B., Ilić-Tomić, T., Senerović, L., Nikodinovic-Runic, J., 2014 Cytotoxic effect of Reseda lutea L.: a case of forgotten remedy. J. Ethnopharmacol $153,125-132$.

Rzadkowska-Bodalska, H., 1969. Flavonoids in flowers of weld (Reseda lutea) III. Identification of compound C. Dissert. Pharm. Pharma. 21, 169-172.

Susplugas-Taillade, C., Susplugas, P., Michel, F., 1988. Anti-inflammatory activity of an ether extract of Reseda phytenma L.: its effect on arachidonic acid metabolism. Pharm. Acta Helv. 63, 59-63.

Woelfle, U., Simon-Haarhaus, B., Merfort, I., Schempp, C.M., 2010. Reseda luteola L. Extract displays antiproliferative and pro-apoptotic activities that are related to its major flavonoids. Phytother. Res. 24, 1033-1036.

Yuldashev, M.P., Batirov, E.K., Malikov, V.M., Yuldashev, N.P., 1996. Flavonoids of Psoralea drupaceae and Reseda luteola. Khim. Prir. Soedin. 6, 949-951. 